missionaries, to which all the great societies refer, and from which some of the bost modical missionaries have hailed. It cannot be too clearly realised, however, that to the piety of its great local physicians and surgeons Edinburgh owes the creation and success of the Society. Abercrombie, Elison, Handyside, Miller, Coldstream, and Benjamin Bell are classical names in Edinburgh medical history, and they were all active promoters of this Divine cause. If anyone doubts the impression for good made on uncivilised or unchristianised nations, he has only to read this book, though it by no means exhausts the statement of medical work done or impression made. One very excellent feature of Mr. Lowe's book is his insistance on the thorough and complete training and qualification of those, whether men or women, who go out to do medical missionary work. Their surgical and obstetrical training should be even more complete than that of average practitioners, seeing that they have no help in consultation or co-operation with others, as in diffeult cases at home. The rapid progress of this Society is gratifying. In 1861 its income was $£ 590$; in $1871, £ 1314$; in 1881, £5506; while during the last decade $£ 15,000$ were raised for special objects. There are at present 170 qualified medical missionaries in active service at home and abroad, whereas before 1871 only thirty were in the field. Can London say that she has done her share in this useful work? The noble and devoted Robert Moffat said that a medical missionary was a missionary and a half, or rather a double missionary. Many other generous testimonies from clerical colleagues to the value of medical pioneering in missionary work are given in these pages, which leave no doubt that, as the early nistory of Christianity was associated with great gifts of healing, so its extension is to be. We earnestly commend this book to the sympathy and attention of our readers.

Handbook for the Instruction of Attendants on the Insane. Prepared by a Sub-committee of the Medico-Psychological Association. London: Baillière, Tindall, and Cox. 1885. Eectures on the Care and Treatment of the Insane, for the Instruction of Attendants and Nurses. By W. C. Willidasson, M.D. Paramatta. Printed at Sydney. 1885.

THE intention of the short manual of sixty pages issued ander the auspices of the Medico-Psychological Association is of the most commendable kind, there being no greater desideratum in the treatment of insanity than well-trained and instructed attendants. The directions given for nursing and general duties are well compiled; while the information in regard to the forms of mental disorder and the directions as to the management of the different mental states are also distinctly good. The epitome of anatomy and physiology, however, with which the handbook begins, is of doubtful value and might confuse rather than instruct. On the whole, the handbook is a decided advance on the usual manuals of rules and instructions in use in asylums.

Dr. Williamson's Lectures are deficient in the amount of instruction and direction given in reference to the special management of the insane, and are redundant in information in regard to the treatment of diseases. They are, however, satisfactory in bearing testimony to the recognition in Australia of the importance of training attendants.

As International Congress of Hydrology and climatology will be held at Biarritz from Oct. 1st to 8th. The work of the Congress will be divided into, and papers read on, the three following sections:- Scientific hydrology, medical hydrology, and climatology. Numerous excursions hare been arranged, and we are assured that a hospitable reception awaits those who attend the meeting from its promoters.

Two deaths from eating poisonous fungi in mistake for mushrooms have just occurred at Nottingham.

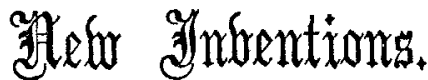

\section{A NEW AND IMPROVED CLAMP FOR HAMORRHOIDS.}

THE method of crushing piles, instead of dealing with them by ligature, was an important advance in rectal surgery, and the question of the best form of clamp has followed naturally upon the adoption of the operation. The use of existing instruments during a term of years led the inventor of the present clamp to consider, with considerable interest, how far the necessities of the operation were met by the crushers at present existing, and how their shortcomings might be rectified. To many surgeons Benham's clamp has 'commended itself by its power, but at best it has always appeared a heavy and unwieldy weapon. To others Allingham's fenestrated crusher has been acceptable, as a distinct improvement, by its greater handiness, as compared with the former; but admirable as this undoubtedly is, there are certain points to which exception may fairly be taken-notably, that the pile seized by the tenaculum has to be drawn through the fenestrum, and that as by necessity a considerable amount of tissue is brought into the area of the crushing bars, a larger surface than is strictly necessary is crushed, and a correspondingly large wound remains to be healed. In the hope of overcoming these objections this new clamp was designed, and after much thought and consideration the principle of the familiar "spanner" or "screwhammer" was adopted as a model. The instrument has been admirably manufactured by Messrs. Maw, Son, and Thompson, of Aldersgate-street, and whatever fault is found with it by expert rectal surgeons or the practitioner at large must be laid to the charge of the inventor, and not to that of the manufacturers. The accompanying woodcut will convey a very excellent idea of the modus operandi. It will be seen that the principle of the lever action has been discarded, and that the crushing power is obtained in a direct line by screw action, as in Allingham's, with this difference, that whereas in the latter the lower bar is forced upon the upper, here the upper bar is drawn down upon the lower. A slow screw has been adopted, as giving greater power to the operator. It may be contended that greater power is obtained with the older instrument, but in the opinion of the writer too much stress has been laid upon the power actually required for the complete destruction of the tissue; and, moreover, actual experiment has shown that the present instrument can be credited with the possession of a positively increased crushing power, while the results obtained have been sufficiently conclusive and successful to warrant the claim advanced for it as an "improved clamp," and as such it is confidently placed at the disposal of the profession.

Chardes John Sirteh, Formerly Surgeon to the Farringdon Dispensary. 